\title{
PERDAS PÓS-COLHEITA EM HORTALIÇAS PROVOCADAS POR DANOS NA REDE VAREJISTA DE SANTARÉM-PA
}

\author{
Antonia Mirian Nogueira de Moura Guerra ${ }^{1^{*}}$, Ana Cecília Moura Costa², Júlia Batista Azevedo \\ Ferreira $^{3}$, Paula Raniele Freitas Tavares ${ }^{4}$, Thaís Silva Vieira ${ }^{5}$
}

\begin{abstract}
RESUMO - As hortaliças estão sujeitas a diversos tipos de danos após a colheita, ocasionados por condições inadequadas de manuseio e armazenamento, doenças e. O objetivo foi avaliar as principais causas de perdas póscolheita em pimentões, batatas e cebolas comercializadas nas feiras e supermercados de Santarém-Pará. O trabalho foi conduzido no comércio varejista em: supermercado, feira da Cohab, feira do Aeroporto Velho e Mercadão 2000. Os danos nas hortaliças foram avaliados e classificados em danos físiológicos, microbiológicos e mecânicos. Em todos os locais avaliados as hortaliças apresentaram danos, que foram responsáveis pelas perdas de forma direta ou indireta. os principais danos em cebola foram talo grosso, bulbos mal formados, flácidos, descoloridos e brotados. Pimentões apresentaram danos como frutos amassados, apodrecidos, esfolados, queimados e atacados por insetos, feridos, murchos, com rachaduras e mal formados. Tubérculos com cortes superficiais não diferiu entre os diferentes locais. Dentre os danos observados nos tubérculos destacam-se as amassaduras, esfoladuras, esverdeamento, má formação e murcha nos comercializados nas feiras, enquanto que no supermercado os danos mais presentes foram os cortes profundos e brotações. Estes resultados revelam a necessidade de investimento na estruturação dos mercados varejistas para promoverem a diminuição das indesejáveis perdas e prejuízos financeiros.
\end{abstract}

Palavras chave: esverdeamento, murchamento, talo grosso.

\section{POST-HARVEST LOSSES ON VEGETABLES DUE TO DAMAGES AT THE SANTARÉM-PA RETAILER NETWORK}

\begin{abstract}
Vegetables are subject to various types of damage after harvest due to inadequate handling and storage conditions, and diseases. The objective was to evaluate the main causes of post-harvest losses in peppers, potatoes and onions marketed in the fairs and supermarkets of Santarém-Pará. The work was conducted in the retail trade in: supermarket, Cohab fair, fair of the Old Airport and Market Mercadão 2000. The damages in the vegetables were evaluated and classified in physiological, microbiological and mechanical damages. In all the evaluated places the vegetables presented damages, that were responsible for the losses of direct or indirect form. The main damage on onions was thick stalk, bulges malformed, flaccid, discolored and sprouted. Chilies presented damages like crushed, rotted, skinned, burned and attacked by insects, injured, withered, cracked and malformed. Tubers with superficial cuts did not differ between the different sites. Among the damages observed in the tubers, the most frequent damages were the deep cuts and sprouts. These results reveal the need for investment in the structuring of the retail markets to promote the reduction of undesirable losses and financial losses.
\end{abstract}

Keywords: greening, thick stalk, wilting.

\footnotetext{
1 Docente do curso de Agronomia da Universidade Federal do Oeste da Bahia, Centro Multidisciplinar Campus de Barra, Av. 23 de Agosto s/nº, Bairro Assunção, CEP: 47100-000, Barra - BA. E-mail: mirianagronoma@hotmail.com.*Autor para correspondência.

${ }^{2}$ Discente do curso de Agronomia da Universidade Federal do Oeste do Pará, Instituto de Biodiversidade e Florestas (Unidade Tapajó), Rua Vera Paz, s/nº, Bairro Salé, CEP:68035-110, Santarém - PA.

${ }^{3}$ Discente do curso de Agronomia da Universidade Federal do Oeste do Pará, Instituto de Biodiversidade e Florestas (Unidade Tapajó), Rua Vera Paz, s/nº, Bairro Salé, CEP:68035-110, Santarém - PA.

${ }^{4}$ Discente do curso de Agronomia da Universidade Federal do Oeste do Pará, Instituto de Biodiversidade e Florestas (Unidade Tapajó), Rua Vera Paz, s/nº, Bairro Salé, CEP:68035-110, Santarém - PA.

${ }^{5}$ Discente do curso de Agronomia da Universidade Federal do Oeste do Pará, Instituto de Biodiversidade e Florestas (Unidade Tapajó), Rua Vera Paz, s/nº, Bairro Salé, CEP:68035-110, Santarém - PA.
} 


\section{INTRODUÇÃO}

Os processos biológicos vitais mantem-se ativos após a colheita em frutas e hortaliças, que continuam tendo elevado teor de água em sua composição química, tornando esses produtos altamente perecíveis (Luengo et al., 2007). Dessa forma, práticas adequadas de manuseio durante as fases de colheita, armazenamento, comercialização e consumo são fundamentais para aumentar o tempo de conservação e reduzir as perdas pós-colheita (Rinaldi, 2011).

Alta perecibilidade dificulta a comercialização e o manuseio em condições ambientais inadequadas acelera a perda de qualidade de hortaliças, apesar da grande diversidade e disponibilidade desses produtos no mercado (Cenci, 2006).

Perdas pós-colheita aliadas a fatores como injúrias mecânicas causadas por embalagens inadequadas e manuseios incorretos que começam na propriedade rural, na colheita do produto, na classificação e seleção das hortaliças, indo até aos consumidores intermediários e finais são principais problemas da cadeia produtiva. Estes fatores são responsáveis pelas elevadas perdas no processo de comercialização e, consequentemente, por grande parte das consideráveis distâncias entre os preços de compra e os de venda dos produtos hortícolas (Chitarra \& Chitarra, 2005). O transporte inadequado, ausência da cadeia do frio, a comercialização a granel, desconhecimento de técnicas de manuseio pré e pós-colheita, o excesso de "toque" pelos consumidores nos produtos, acúmulo de produtos nas gôndolas de exposição de varejo são agravantes às perdas de hortaliças (Soares 2009). Aliado a todos estes fatores, as altas temperaturas aumentam a velocidade das reações bioquímicas, dessa forma, o produto murcha e estraga mais rapidamente, o que reduz a sua vida útil (Luengo et al., 2007).

Os níveis de perdas entre a colheita e a chegada à mesa do consumidor, no Brasil, são de $35 \mathrm{a} 40 \%$, enquanto em outros países, como nos Estados Unidos, as perdas não ultrapassam 10\% (Vilela et al., 2003a; Vilela et al., 2003b; Melo \& Vilela, 2007; Luengo \& Calbo, 2011; Rinaldi, 2011).

Santarém possui uma população estimada no ano de 2017 de 296.302 habitantes (IBGE, 2010) e é considerado o principal município do Oeste do Pará, onde a agropecuária baseada na produção de mandioca, de grãos (soja e milho), bovinocultura (carne), avicultura (pequena escala) e agricultura familiar. A produção de hortaliças é modesta, e o fornecimento para atender a população vem de estados das regiões Sudeste, Nordeste e Centro-Oeste através de transporte rodoviário por estradas em péssimo estado de conservação, o que leva alguns dias para a chegada dos produtos, favorecendo o aumento dos danos e das perdas.

Comumente a comercialização de hortaliças nas cidades brasileiras interioranas é pouco organizada e deficiente de informações, além de dependerem do fluxo de fornecimento das grandes centrais de abastecimento. Escassas são as informações na literatura acerca de perdas pós-colheita em hortaliças nas cidades interioranas, ficando esses dados restritos apenas as grandes centrais de abastecimento das regiões Sul e Sudeste. Portanto, o objetivo desse trabalho é avaliar as causas de perdas pós-colheita em hortaliças (batata, cebola e pimentão) comercializadas nas feiras e supermercados de Santarém - PA, a fim de subsidiar estudos futuros e propor medidas que minimizem as perdas destas hortaliças.

\section{MATERIAL E MÉTODOS}

O trabalho foi conduzido no comércio varejista de Santarém - PA $\left(02^{\circ} 24^{\prime} 52^{\prime \prime} \mathrm{S}\right.$ de latitude; $54^{\circ} 42^{\prime} 36^{\prime \prime}$ $\mathrm{W}$ e $152 \mathrm{~m}$ de altitude), a temperatura média anual é de $25^{\circ} \mathrm{C}$ e umidade relativa do ar de $86 \%$ (Silva \& Nechet, 2006), sendo os locais avaliados: supermercado, Feira da Cohab, Feira do Aeroporto Velho e Mercadão 2000.

As avaliações foram realizadas antes que as hortaliças fossem expostas para a comercialização. Qualidade inicial dos produtos foi avaliadas com a finalidade de identificar os possíveis danos que representam fontes potenciais de perdas. Os danos nas hortaliças foram avaliados e classificados em danos fisiológicos (aqueles que ocorreram devido alguma interferência ao metabolismo da planta, ocorrendo tanto em condições de campo quanto durante o armazenamento); danos microbiológicos (foram aqueles ocasionados por microrganismos e insetos originários do campo ou do processo de embalagem e armazenamento) e danos mecânicos (tratou-se daqueles que ocorrem devido a alguma interferência a nível de campo ou manuseio inadequado, ocorrendo tanto em condições de campo ou mesmo durante o beneficiamento, armazenamento e comercialização). 
A amostragem foi realizada de forma aleatória em parte do estoque total. Uma amostra de quatro caixas de $20 \mathrm{~kg}$ de cada hortaliça foi utilizada para avaliações e pesagens. As hortaliças avaliadas foram cebola, batata e pimentão.

\section{Pimentão (Capsicum annuum L.)}

$\mathrm{Na}$ amostra foram caracterizados os atributos de interesse para grupo (de acordo com o formato do fruto: retangular, cônico e quadrado), subgrupo (conforme a coloração do fruto: vermelho, amarelo, laranja, verde, creme e roxo) (Souza, 2004), danos mecânicos, fisiológicos e microbiológicos (Lana et al., 2006).

Os danos fisiológicos foram murcho (flacidez, fruto sem turgescência, enrugado ou sem brilho), queimado (fruto que apresenta área descolorida e/ou necrosada, provocada pela ação do sol e/ou geada), dano não cicatrizado (ferida ou lesão não cicatrizada de origem diversa), manchado (alteração na coloração normal do fruto não proveniente da evolução do estágio de maturação do mesmo), deformado (desvio acentuado na forma característica da cultivar), estrias (fenda superficial na cutícula, de natureza não progressiva), ferimento cicatrizado (ferida ou lesão cicatrizada de origem diversa). Danos mecânicos como ferimentos (cortes profundos ou superficiais), esfoladuras (frutos que apresentam exposição dos tecidos internos por falta de pele), amassados ("estouro" ou rachadura do fruto), dano por geada (fruto que apresenta perda de consistência e zonas necrosadas provocadas pela ação da geada). Danos microbiológicos como apodrecimento (dano patológico e/ou fisiológico que implique em qualquer grau de decomposição, desintegração e fermentação dos tecidos), ataque por insetos (frutos com sintomas de ataque por insetos), dano mecânico + insetos (frutos com danos mecânicos e com sintomas de ataque de insetos) (Lana et al., 2006).

A proporção de cada um destes itens foi expressa em \% (massa de frutos com dano em relação à massa total da caixa).

\section{Cebola (Allium cepa L.)}

As porções foram pesadas separadamente e a proporção calculada em \% da massa total da caixa. Os bulbos foram separados de acordo com os danos descritos conforme Souza (2004), e foram enquadrados em um único tipo de dano.
Danos fisiológicos foram talo grosso, brotado (quando o bulbo apresenta emissão do broto visível acima do colo), colo mal formado (formação incompleta do colo do bulbo), flacidez (falta de turgescência, ausência da rigidez normal do bulbo), descoloração (desvio parcial ou total na cor característica da cultivar, incluindo o esverdeamento), deformado (bulbo que apresenta formato diferente do típico da cultivar). Os danos microbiológicos foram classificados em podridão (dano patológico e/ou fisiológico que implique em qualquer grau de decomposição, desintegração ou fermentação dos tecidos), mancha negra (área enegrecida em virtude do ataque de fungos nas catáfilas externas ou no colo do bulbo), mofado (bulbo que apresenta fungo nas catáfilas externas). Como danos mecânicos foram consideradas as lesões (de origem mecânica, observada nas catáfilas do bulbo), cortes (superiores $1 \mathrm{~cm}$ de profundidade, provenientes do manuseio inadequado durante a colheita e nas etapas de póscolheita), amassaduras (originárias tanto durante o processo de colheita quanto no armazenamento e transporte devido a compressão imposta pelo enfardamento), esfoladuras (lesões mais profundas no bulbo originárias durante os processos de colheita, lavagem, seleção, embalagem e transporte).

A proporção de cada um destes itens foi expressa em \% (massa de bulbos com dano em relação à massa total da caixa).

\section{Batata (Solanum tuberosum L.)}

Para cada caixa de batatas, os tubérculos foram classificados quanto aos danos mecânicos, fisiológicos e microbiológicos (Souza, 2004).

Foram considerados como danos fisiológicos, tubérculos murchos, esverdeados (quando a área afetada alcançar mais de 5\% da superfície do tubérculo e profundidade em mais de $3 \mathrm{~mm}$ da polpa), coração negro (mancha de conformação irregular e de coloração cinza que ocorre no interior do tubérculo), brotado ou embonecado (crescimento secundário e desuniforme do tubérculo com brotos), mancha chocolate (mancha de cor marrom, semelhante a do chocolate que se observa na parte interna do tubérculo), vitrificação (tubérculo que apresentava a polpa fibrosa ou cristalizada), mal formado (desuniformidade severa de desenvolvimento do tubérculo com extremos pronunciados), coração oco (cavidade interna, causada por crescimento excessivamente rápido do tubérculo). Como danos 
microbiológicos foram considerados a podridão seca (necrose nos tecidos, de aspecto desidratado ou mumificado), podridão úmida (necrose dos tecidos resultando em aspecto aquoso, mole e odor fétido), rizoctonia (agregados negros (escleródios) aderidos à pele do tubérculo causado pelo fungo Rhizoctonia solani, superior a $5 \%$ da superfície do tubérculo), perfurações e broca alfinete (ataque por insetos de solo fazem furos nos tubérculos que ficam com aparência de alfinetados). Foram classificados como danos mecânicos os cortes superficiais (a lesão não afetar mais de $10 \%$ do tubérculo), cortes profundos (quando a lesão persiste após a remoção de $3 \mathrm{~mm}$ do tecido e produz uma perda superior a $5 \%$ em peso para se eliminar o dano), esfoladuras (tubérculo que apresenta exposição dos tecidos internos por falta de pele, sendo originados quando a cura é realizada de maneira inadequada) e rachaduras e amassados ("estouro" ou rachadura do tubérculo causada por crescimento excessivo relacionado a causas ambientais, como falta ou excesso de água, ou mesmo atividades mecanizadas) (Souza, 2004).

A proporção de cada um destes itens foi expressa em \% (massa de tubérculos com dano em relação à massa total da caixa).

Adotou-se o delineamento inteiramente casualizado com quatro repetições. Foram comparados entre si os locais de coleta de dados (supermercados; Feira da Cohab; Feira do Aeroporto Velho e Mercadão 2000). Os dados foram submetidos à análise de variância e as médias dos locais foram comparadas entre si pelo teste de Tukey a $5 \%$ de probabilidade.

\section{RESULTADOS E DISCUSSÃO}

Danos foram observados em hortaliças oriundas de todos os locais avaliados, aos quais atribuímos como responsáveis pelas perdas de forma direta ou indireta. Conforme relatos dos proprietários dos estabelecimentos comerciais verificou-se a cebola e a batata foram adquiridas exclusivamente de produtores externos ao Estado, principalmente nas CEASAs de São Paulo - SP, de Belo Horizonte - MG e de Goiânia - GO, enquanto que para o pimentão, parte foi oriundo das CEASAs, e parte foi obtida dos produtores locais que possuem contratos de comercialização com o supermercado. Essa forma de abastecimento apresenta grandes problemas de sazonalidade de oferta e de preço, bem como de qualidade, pois o transporte, exclusivamente rodoviário, contribui para o incremento nos danos.

Tuberculos oriundos das feiras apresentaram maior incidência de danos (de 50 a 55\%) em relação ao supermercado (45\%) (Tabela 1). Os tubérculos comercializados nas feiras não diferiram entre si para os danos mecânicos, porém na feira do Aeroporto Velho ocorreu uma tendência de maior incidência destes. Já os danos fisiológicos e microbiológicos foram mais presentes naqueles expostos no supermercado em relação às demais (Tabela 1). Tofanelli et al. (2009) observaram perdas de $9,9 \%$ nas batatas comercializadas na rede varejista de Mineiros - GO, esse menor volume foi atribuído a maior vida pós-colheita. Por outro lado, Almeida et al. (2012b) constataram que na rede varejista de Areia - PB as perdas devido a danos em batata alcançaram $29,08 \%$. A alta incidência de danos aqui encontrados se deve a aquisição, muitas vezes um produto de qualidade inferior, bem como ao longo transporte rodoviário em condições inadequadas que levam a redução da qualidade final.

A presença de tubérculos com cortes superficiais não diferiu entre os diferentes locais, porém destacaramse as amassaduras, esfoladuras, esverdeamento, má formação e murcha nos tubérculos comercializados nas feiras, enquanto que no supermercado os danos mais presentes foram os cortes profundos e brotados (Tabela 1). Luengo et al. (2003) afirmaram que os danos mecânicos, além de prejudicar a aparência do produto diretamente, diminuindo o seu valor comercial, constituem-se na principal via de penetração de agentes patogênicos, que causam deterioração e perda do alimento. Quando os tubérculos são expostos à luz, passam por um processo de esverdeamento, resultante da síntese da clorofila (Fernandes et al., 2011). O manuseio excessivo durante as etapas de colheita, lavagem e beneficiamento, além de uma cura mal feita são responsáveis pela maior incidência de cortes na superfície dos tubérculos. Além da carga de danos que já vem das etapas de produção e beneficiamento, a longa viagem entre os centros de distribuição e a cidade de Santarém, através de rodovias em péssimo estado de conservação, associada com a ausência de climatização durante o trajeto, são agravantes para intensificar os danos.

Quanto aos danos microbiológicos, não houve diferença entre os locais analisados, todavia, na Feira 
Tabela 1 - Porcentagem de danos em tubérculos de batata comercializados na rede de comércio varejista de Santarém - PA

\begin{tabular}{|c|c|c|c|c|c|c|}
\hline \multirow{3}{*}{ Variáveis } & \multicolumn{4}{|c|}{ Locais avaliados } & \multirow[b]{3}{*}{ DMS } & \multirow[b]{3}{*}{ Erro } \\
\hline & Feira da & Feira do Mercadão & Feira do & Rede de & & \\
\hline & Cohab & $2000 \quad A$ & Aeroporto Velho & Supermercados & & \\
\hline & \multicolumn{6}{|c|}{ Ausência e presença de danos (\%) } \\
\hline Com danos & $50,00 \mathrm{a}$ & $52,00 \mathrm{a}$ & $55,00 \mathrm{a}$ & $45,00 \mathrm{~b}$ & 6,00 & 2,60 \\
\hline \multirow[t]{2}{*}{ Sem danos } & $50,00 \mathrm{~b}$ & $48,00 \mathrm{~b}$ & $45,00 \mathrm{~b}$ & $55,00 \mathrm{a}$ & 4,50 & 2,90 \\
\hline & \multicolumn{6}{|c|}{ Tipos de danos $(\%)$} \\
\hline Mecânicos & $56,50 \mathrm{a}$ & $65,00 \mathrm{a}$ & $71,75 \mathrm{a}$ & $17,50 \mathrm{~b}$ & 26,23 & 6,24 \\
\hline Fisiológicos & $28,00 \mathrm{ab}$ & $18,75 \mathrm{bc}$ & $5,00 \mathrm{c}$ & $40,00 \mathrm{a}$ & 18,94 & 4,51 \\
\hline \multirow[t]{2}{*}{ Microbiológicos } & $15,50 \mathrm{~b}$ & $16,25 b$ & $23,25 b$ & $42,50 \mathrm{a}$ & 13,54 & 3,22 \\
\hline & \multicolumn{6}{|c|}{ Danos mecânicos (\%) } \\
\hline Amassados/rachados & $32,50 \mathrm{a}$ & $19,75 \mathrm{a}$ & $32,00 \mathrm{a}$ & $2,75 b$ & 12,98 & 3,09 \\
\hline Cortes profundos & $17,50 \mathrm{~b}$ & $25,75 b$ & $18,00 \mathrm{~b}$ & $48,50 \mathrm{a}$ & 13,37 & 3,18 \\
\hline Esfoladuras & $21,75 \mathrm{a}$ & $30,25 \mathrm{a}$ & $22,25 \mathrm{a}$ & $23,75 b$ & 10,86 & 2,58 \\
\hline \multirow[t]{2}{*}{ Cortes superficiais } & $28,25 \mathrm{a}$ & $24,25 \mathrm{a}$ & $27,75 \mathrm{a}$ & $24,75 a$ & 11,02 & 2,62 \\
\hline & \multicolumn{6}{|c|}{ Danos fisiológicos (\%) } \\
\hline Esverdeado & $55,50 \mathrm{a}$ & $53,70 \mathrm{a}$ & $46,50 \mathrm{a}$ & $38,25 \mathrm{a}$ & 10,75 & 2,55 \\
\hline Mal formado & $19,00 \mathrm{a}$ & $17,55 \mathrm{a}$ & $23,75 a$ & $20,75 a$ & 11,37 & 2,70 \\
\hline Murchas & $16,50 \mathrm{a}$ & $14,75 \mathrm{a}$ & $15,25 \mathrm{a}$ & $5,00 \mathrm{a}$ & 11,73 & 2,79 \\
\hline \multirow[t]{2}{*}{ Brotado/embonecados } & $9,00 \mathrm{~b}$ & $14,00 \mathrm{~b}$ & $14,50 \mathrm{~b}$ & $36,00 \mathrm{a}$ & 9,45 & 2,25 \\
\hline & \multicolumn{6}{|c|}{ Danos microbiológicos (\%) } \\
\hline Podridão úmida & $33,00 \mathrm{a}$ & $64,50 \mathrm{a}$ & $51,50 \mathrm{a}$ & $67,00 \mathrm{a}$ & 34,29 & 8,16 \\
\hline Perfuração por brocas & $67,00 \mathrm{a}$ & $35,50 \mathrm{a}$ & $48,50 \mathrm{a}$ & $33,00 \mathrm{a}$ & 48,86 & 11,63 \\
\hline
\end{tabular}

Médias seguidas de mesma letra minúscula na linha não diferem estatisticamente entre si pelo teste de Tukey a 5\% de probabilidade. DMS: diferença mínima significativa.

da Cohab houve maior incidência de tubérculos perfurados por brocas, enquanto que maior presença de batatas com podridão úmida foi observada na Feira do Mercadão 2000 e Supermercado (Tabela 1). Almeida et al. (2012b) constataram que os agentes fitopatológicos foram os responsáveis pelas maiores perdas em batatas em Areia - PB, onde as doenças ocasionaram diversas interferências tanto nos ambientes de produção quanto naqueles destinados ao escoamento e à comercialização de batatas denotando a baixa qualidade e quantidade.

Em todas as cebolas avaliadas foi constatado algum tipo de dano, e no supermercado houve maior incidência destes em relação as feiras $(27,00 \%)$. Tofanelli et al. (2009) encontram perdas de aproximadamente $10 \% \mathrm{em}$ cebolas comercializadas no município de Mineiros $\mathrm{GO}$, e boa parte destas foram atribuídas aos danos que vem do campo. Em trabalho de identificação de sistemas de produção de cebola nos principais estados produtores, Vilela et al. (2003b) constataram níveis médios de perdas de $30 \%$, resultantes de descarte do produto no processo de classificação, por não atender aos padrões de qualidade exigidos pelo mercado, o que mostra uma consonância com os dados obtidos em nosso estudo.

Bulbos com talo grosso e mal formados foram mais frequentes no Supermercado, os flácidos foram mais presentes na Feira da Cohab e na Feira do aeroporto, os descoloridos estavam em maior quantidade nas feiras e a alta incidência de brotados foi exceção apenas no Supermercado. Observouse uma maior quantidade de danos mecânicos na Feira do Mercadão 2000 e Supermercado, de danos fisiológicos na Feira do Mercadã0 2000 e Feira da Cohab, danos microbiológicos no Supermercado e Feira da Cohab. No supermercado foi constatada a maior incidência de todos os tipos de danos mecânicos. Não houve diferença estatística entre os locais para podridão e bulbos mofados (Tabela 2). Os danos mecânicos e fisiológicos em si não inviabilizam a comercialização, mas, a incidência de injúrias mecânicas é uma das causas mais importantes de perdas pós-colheita porque afeta diretamente a aparência do produto e acelera diversos processos fisiológicos, como a desidratação e a respiração, levando ao murchamento e, também, pode favorecer o desenvolvimento de microrganismo, levando à podridão. 
Tabela 2 - Porcentagem de danos em bulbos de cebola comercializados na rede de comércio varejista de Santarém - PA

\begin{tabular}{|c|c|c|c|c|c|c|}
\hline \multirow[b]{2}{*}{ Variáveis } & \multicolumn{4}{|c|}{ Locais avaliados } & \multirow[b]{2}{*}{ DMS } & \multirow[b]{2}{*}{ Erro } \\
\hline & $\begin{array}{l}\text { Feira da } \\
\text { Cohab }\end{array}$ & $\begin{array}{c}\text { Feira do Mercadão } \\
2000\end{array}$ & $\begin{array}{l}\text { Feira do } \\
\text { Aeroporto Velho }\end{array}$ & $\begin{array}{c}\text { Rede de } \\
\text { Supermercados }\end{array}$ & & \\
\hline & \multicolumn{6}{|c|}{ Ausência e presença de danos (\%) } \\
\hline Sem danos & $78,00 \mathrm{a}$ & $76,00 \mathrm{a}$ & $74,00 \mathrm{a}$ & $83,00 \mathrm{a}$ & 7,00 & 3,80 \\
\hline \multirow[t]{2}{*}{ Com danos } & $22,00 \mathrm{~b}$ & $24,00 b$ & $26,00 \mathrm{~b}$ & $27,00 \mathrm{a}$ & 7,90 & 1,90 \\
\hline & \multicolumn{6}{|c|}{ Tipos de danos $(\%)$} \\
\hline Mecânicos & $25,25 b$ & $46,50 a$ & $31,00 \mathrm{~b}$ & $32,50 \mathrm{ab}$ & 15,32 & 3,64 \\
\hline Fisiológicos & $32,00 \mathrm{a}$ & $33,00 \mathrm{a}$ & $29,75 \mathrm{a}$ & $21,00 \mathrm{a}$ & 12,28 & 2,92 \\
\hline \multirow[t]{2}{*}{ Microbiológicos } & $42,50 \mathrm{a}$ & $20,50 \mathrm{~b}$ & $37,50 \mathrm{a}$ & $46,50 \mathrm{a}$ & 14,29 & 3,40 \\
\hline & \multicolumn{6}{|c|}{ Danos mecânicos (\%) } \\
\hline Amassados & $12,25 b$ & $12,50 \mathrm{~b}$ & $15,75 b$ & $34,50 \mathrm{a}$ & 9,22 & 2,19 \\
\hline Lesões & $4,00 \mathrm{~b}$ & $9,50 \mathrm{ab}$ & $8,00 \mathrm{~b}$ & $16,25 \mathrm{a}$ & 8,08 & 1,92 \\
\hline Esfoladuras & $4,75 b$ & $17,75 \mathrm{a}$ & $3,75 b$ & $25,50 \mathrm{a}$ & 7,88 & 1,87 \\
\hline \multirow[t]{2}{*}{ Cortes } & $4,25 \mathrm{~b}$ & $6,75 b$ & $3,50 b$ & $23,75 \mathrm{a}$ & 9,87 & 2,35 \\
\hline & \multicolumn{6}{|c|}{ Danos fisiológicos (\%) } \\
\hline Descolorido & $14,50 \mathrm{ab}$ & $19,75 \mathrm{a}$ & $13,00 \mathrm{ab}$ & $8,25 b$ & 10,00 & 2,38 \\
\hline Talo grosso & $9,50 \mathrm{~b}$ & $10,25 b$ & $9,00 \mathrm{~b}$ & $23,25 \mathrm{a}$ & 6,65 & 1,58 \\
\hline Mal formado & $41,50 \mathrm{~b}$ & $38,75 b$ & $42,75 b$ & $64,00 \mathrm{a}$ & 16,41 & 3,90 \\
\hline Flacidez & $25,00 \mathrm{a}$ & $18,25 b$ & $23,25 \mathrm{ab}$ & $1,75 \mathrm{c}$ & 6,59 & 1,56 \\
\hline \multirow[t]{2}{*}{ Brotado } & $9,50 \mathrm{a}$ & $10,50 \mathrm{a}$ & $12,00 \mathrm{a}$ & $2,75 b$ & 4,40 & 1,04 \\
\hline & \multicolumn{6}{|c|}{ Danos microbiológicos (\%) } \\
\hline Podridão & $35,50 \mathrm{a}$ & $47,50 \mathrm{a}$ & $35,75 \mathrm{a}$ & $40,00 \mathrm{a}$ & 10,74 & 2,55 \\
\hline Mofado & $64,50 \mathrm{a}$ & $52,50 \mathrm{a}$ & $64,25 \mathrm{a}$ & $60,00 \mathrm{a}$ & 23,84 & 5,76 \\
\hline
\end{tabular}

Médias seguidas de mesma letra minúscula na linha não diferem estatisticamente entre si pelo teste de Tukey a 5\% de probabilidade. DMS: diferença mínima significativa.

Isso evidencia que as cebolas que chegam a rede varejista de Santarém já traz uma elevada carga de danos que certamente se constituirão como causas potenciais de perdas. Almeida et al. (2012a) constataram que injúrias fitopatológicas e o brotamento dos bulbos foram as principais de perdas nas cebolas comercializadas no estado da Paraíba, uma vez que a embalagens utilizadas são sacos de ráfia ou nylon que favorecem corte e injurias que facilitam a contaminação e proliferação de microrganismos.

Todos os pimentões avaliados apresentavam formato retangular e cor verde. Maior incidência de danos nos pimentões foram observadas nas feiras em relação ao supermercado. Maior porcentagem de danos mecânicos na Feira do Aeroporto Velho e feira da Conab, de danos fisiológicos na Feira do Mercadão 2000, feira e supermercado. Não ouve diferença entre as porcentagens de danos entre os locais (Tabela 3 ). Esses resultados assemelham-se aos encontrados por Ribeiro et al. (2011), onde os danos mecânicos provenientes de abrasões tiveram valor expressivo na perda de pimentões. Almeida et al. (2012b) também encontraram que danos mecânicos (amassamento), fisiológicos (amadurecimento, perda de cor, massa e textura) ataque por patógenos foram responsáveis por perdas de $60 \%$ em pimentões comercializados em Areia - PB.

A presença de frutos amassados e apodrecidos não diferiu estatisticamente entre os locais. Por outro lado, aqueles com esfoladuras, queimaduras e atacados por insetos forma mais presentes na Feira do Mercadão 2000. Frutos feridos e murchos apresentaram-se em maior quantidade na Feira do Aeroporto Velho, enquanto que no Supermercado foi frequente a presença frutos com rachaduras e mal formados (Tabela 3). Lanna et al. (2006) observaram perdas da ordem de $30 \%$ devido a danos mecânicos oriundos de impactos e compressão nos frutos.

As condições de cultivo de pimentão na região, nas quais os produtores conduzem as plantas a pleno sol, favoreceram a queima e descoloração dos frutos. Além disso, as perdas ocasionadas por desordens 
Tabela 3 - Porcentagem de danos em frutos de pimentão comercializados na rede de comércio varejista de Santarém - PA

\begin{tabular}{|c|c|c|c|c|c|c|}
\hline \multirow[b]{2}{*}{ Variáveis } & \multicolumn{4}{|c|}{ Locais avaliados } & \multirow[b]{2}{*}{ DMS } & \multirow[b]{2}{*}{ Erro } \\
\hline & $\begin{array}{l}\text { Feira da } \\
\text { Cohab }\end{array}$ & $\begin{array}{c}\text { Feira do Mercadão } \\
2000\end{array}$ & $\begin{array}{l}\text { Feira do } \\
\text { Aeroporto Velho }\end{array}$ & $\begin{array}{c}\text { Rede de } \\
\text { Supermercados }\end{array}$ & & \\
\hline & \multicolumn{6}{|c|}{ Ausência e presença de danos (\%) } \\
\hline Sem danos & $62,00 \mathrm{c}$ & $65,00 \mathrm{~b}$ & $68,00 \mathrm{~b}$ & $70,00 \mathrm{a}$ & 1,90 & 3,80 \\
\hline \multirow[t]{2}{*}{ Com danos } & $38,00 \mathrm{a}$ & $35,00 \mathrm{a}$ & $32,00 \mathrm{a}$ & $30,00 \mathrm{~b}$ & 6,30 & 1,90 \\
\hline & \multicolumn{6}{|c|}{ Tipos de danos $(\%)$} \\
\hline Mecânicos & $51,25 \mathrm{a}$ & $39,25 b$ & $58,75 \mathrm{a}$ & $34,00 b$ & 10,57 & 2,51 \\
\hline Fisiológicos & $29,50 \mathrm{ab}$ & $37,25 \mathrm{a}$ & $10,00 \mathrm{~b}$ & $30,75 \mathrm{ab}$ & 27,08 & 6,44 \\
\hline \multirow[t]{2}{*}{ Microbiológicos } & $19,25 \mathrm{a}$ & $24,00 \mathrm{a}$ & $31,25 \mathrm{a}$ & $35,25 \mathrm{a}$ & 26,27 & 6,25 \\
\hline & \multicolumn{6}{|c|}{ Danos mecânicos (\%) } \\
\hline Amassados & $50,00 \mathrm{a}$ & $36,75 a$ & $45,00 \mathrm{a}$ & $37,50 \mathrm{a}$ & 23,92 & 5,96 \\
\hline Feridos/cortes & $33,25 \mathrm{bc}$ & $36,00 \mathrm{c}$ & $52,50 \mathrm{a}$ & $43,75 \mathrm{ab}$ & 19,79 & 4,71 \\
\hline \multirow[t]{2}{*}{ Esfoladuras } & $16,75 \mathrm{ab}$ & $27,25 \mathrm{a}$ & $0,00 \mathrm{~b}$ & $16,25 \mathrm{ab}$ & 17,48 & 4,16 \\
\hline & \multicolumn{6}{|c|}{ Danos fisiológicos (\%) } \\
\hline Rachaduras & $1,75 b$ & $4,25 b$ & $3,00 \mathrm{~b}$ & $34,75 \mathrm{a}$ & 9,62 & 2,29 \\
\hline Queimaduras & $28,50 \mathrm{a}$ & $49,00 \mathrm{a}$ & $25,25 \mathrm{a}$ & $4,50 \mathrm{a}$ & 36,83 & 8,76 \\
\hline Estrias & $30,75 \mathrm{a}$ & $8,75 \mathrm{ab}$ & $10,25 b$ & $34,75 \mathrm{ab}$ & 23,96 & 5,70 \\
\hline Mal formado & $13,00 \mathrm{a}$ & $17,25 \mathrm{a}$ & $6,25 \mathrm{a}$ & $26,00 \mathrm{a}$ & 29,97 & 7,13 \\
\hline \multirow[t]{2}{*}{ Murchas } & $32,50 \mathrm{ab}$ & $20,75 b$ & $47,75 \mathrm{a}$ & $0,00 \mathrm{c}$ & 16,84 & 4,01 \\
\hline & \multicolumn{6}{|c|}{ Danos microbiológicos (\%) } \\
\hline Apodrecimento & $71,00 \mathrm{a}$ & $57,50 \mathrm{a}$ & $87,00 \mathrm{a}$ & $61,25 \mathrm{a}$ & 43,05 & 10,25 \\
\hline Ataque por insetos & $29,00 \mathrm{a}$ & $42,50 \mathrm{a}$ & $13,00 \mathrm{a}$ & $38,75 a$ & 49,52 & 11,79 \\
\hline
\end{tabular}

Médias seguidas de mesma letra minúscula na linha não diferem estatisticamente entre si pelo teste de Tukey a 5\% de probabilidade. DMS: diferença mínima significativa.

fisiológicas aconteceram principalmente pela perda de água e da textura originais, tornando os produtos imprestáveis para o comércio e consumo, devem-se as condições de comercialização e armazenamento com ausência da cadeia de frio, ao longo intervalo de exposição dos frutos no varejo e as elevadas temperaturas da cidade de Santarém. Lanna et al. (2006) constataram que murchamento foi a principal causa de descarte dos frutos de pimentão na rede varejista de Brasília. Para Silva \& Giordano (2000), os danos mecânicos, além da perda quantitativa, reduzem a qualidade dos tomates e pimentões, pois os frutos amassados são facilmente contaminados por fungos e bactérias. Lanna et al. (2006) relatam que os principais bactérias causadoras de doenças em frutos pimentão na etapa de pós-colheita são dos gêneros: Phytophtora spp., Erwinia spp. Colletotrichum spp. Em pimentões comercializados na rede varejista de Viçosa-MG foram observadas que doenças pós-colheita causadas pelos patógenos Erwinia sp. e Colletotrichum sp. ocasionaram perdas de $86,5 \%$ (Marques et al., 2005). Para Lourenzani \& Silva (2004), as altas perdas de hortaliças no varejo podem ser atribuídas, na sua maioria, ao manejo e acondicionamento inadequados, bem como também à classificação e padronização dos produtos insuficientes. Batatas e pimentões comercializados nas feiras livres de Santarém apresentam maior porcentagem de danos, em relação aos frutos comercializados em supermercado. O que revela a necessidade de estruturação deste agente de comercialização com a finalidade de reduzir perdas finais e garantir melhores rendimentos aos varejistas. Danos são provocados pelo manuseio excessivo e descuidado com as hortaliças durante a colheita, lavagem, seleção e transporte; uso de embalagens como sacos plásticos ou de ráfia, e engradados de madeira; volume excessivo do produto na embalagem; sobreposição de sacos e caixas durante o transporte; empilhamento inadequado durante a exposição e comercialização. Também as condições climáticas da região, com excessiva umidade, favoreceu os apodrecimentos e a presença de lesões.

Conforme relataram Vilela et al. (2003a), na rede varejista, os depósitos não oferecem as condições satisfatórias; os funcionários não estão treinados para 
lidar com as hortaliças, por isso praticam formas incorretas de manuseio, despejando os produtos nas gôndolas sem os cuidados necessários, o que resulta em ferimentos ou amassamentos.

\section{CONCLUSÕES}

Em todos os locais avaliados foram constatados danos que levaram a perda pós-colheita em pimentão, batata e cebola na rede varejista de Santarém-PA.

Há necessidade de uma estruturação dos mercados varejistas a fim de promover a redução das indesejáveis perdas.

Melhorar as condições de armazenamento, melhorar a classificação e padronização e a qualidade dos produtos, a adoção de embalagens adequadas e assistência técnica para a orientação dos produtores rurais e proprietários de bancas são ações que ajudarão a reduzir danos potenciais.

Neste sentido, as informações produzidas neste trabalho poderão servir de subsídio à elaboração e implantação de programas de combate às perdas de hortaliças frescas no mercado de Santarém, semelhante ao que já vem sendo realizado em outras regiões brasileiras.

\section{AGRADECIMENTOS}

A Rede CR de Supermercados e aos comerciantes das feiras, por gentilmente, nos ter permitido a execução das atividades de pesquisa e coleta de dados em suas dependências. Ao CNPq pelo consentimento das bolsas de iniciação científica.

\section{LITERATURA CITADA}

ALMEIDA, E. I. B.; LUCENA, H. H.; RIBEIRO, W. S.; OLIVEIRA, M. R. T.; BRBOSA, J. A. Análise das perdas de caule, folhas e frutos de hortaliças frescas comercializadas na rede varejista de Areia (PB). Revista Brasileira de Agropecuária Sustentável (RBAS), v. 2, n. 2, p. 81-91, Dezembro, 2012.

ALMEIDA, E. I. B.; RIBEIRO, W. S.; COSTA, L. C.; LUCENA, H. H.; BRBOSA, J. A. Levantamento de perdas em hortaliças frescas na rede varejista de Areia (PB). Revista Brasileira de Agropecuária Sustentável (RBAS), v. 2, n. 1, p. 53-60, Julho, 2012.
ALVARENGA, J. O. Padronização, Classificação e Rotulagem de Frutas e Hortaliças. In: ABRACEN, Associação Brasileira das Centrais de Abastecimento. Manual Operacional dos Ceasas. Belo Horizonte: AD2 editora, 2011.

ANDREUCCETTI, C.; FERREIRA, M. D.; GUTIERREZ, A. S. D.; TAVARES, M. 2005.

Caracterização da comercialização de tomate de mesa na Ceagesp: perfil dos atacadistas. Horticultura Brasileira, n. 23, p. 324-328, 2005.

CEASA-RJ (Rio de Janeiro). Perdas de hortaliças no mercado atacadista do Rio de Janeiro. 2008.

Artigos. Disponível em: $<$ http://

www.ceasario.gov.br>. Acesso em: 13 dez. 2013.

CHITARRA, M. I. F.; CHITARRA, A. B. Póscolheita de frutas e hortaliças: glossário. Lavras: UFLA, 2006.

FAO (Food and Agriculture Organization).

Relatório: Desperdício de alimentos em 2016. Disponível em: $<$ http://www.fao.org.> . Acesso em 18 de agosto de 2016.

FILGUEIRA, F. A. R. Novo manual de olericultura: agrotecnologia moderna na produção e comercialização de hortaliças. 3. ed. Viçosa: UFV, 2008. 421p.

GUERRA, A. M. N. M.; FERREIRA, J. B. A.; COSTA, A. C. M.; TAVARES, P. R. F.; MARACAJÁ, P. B.; COELHO, D. C.; ANDRADE, M. E. L. Perdas pós-colheita em tomate, pimentão e cebola no mercado varejista de Santarém - PA. ACSA Agropecuária Científica no SemiÁrido, v. 10, n. 3, p. 08-17, jul - set, 2014.

INSTITUTO BRASILEIRO DE GEOGRAFIA E ESTATÍSTICA - IBGE. Censo Agropecuário 2010. Disponível em: http://cidades.ibge.gov.br/xtras/ temas.php?lang $=\&$ codmun $=150680 \&$ idtema $=130 \&$ search $=$ para $\mid$ santarem $/$ estimativa-dapopulacao-2015-. Acesso em: 17 de agosto de 2015.

LANA, M. M.; MOITA, A. W.; SOUZA, G. S.; NASCIMENTO, E. F.; MELO, M. F. Identificação das causas de perdas pós-colheita de tomate no varejo em Brasília-DF. Boletim de Pesquisa e Desenvolvimento, 16. Embrapa Hortaliças, Brasília, 2006a. 25p. 
LANA, M. M.; MOITA, A. W.; SOUZA, G. S.; NASCIMENTO, E. F.; MELO, M. F. Identificação das causas de perdas pós-colheita de pimentão no varejo. Boletim de Pesquisa e Desenvolvimento, 17. Brasília: Embrapa Hortaliças, 2006b. 23p.

LANA, M. M.; MOITA, A. W.; NASCIMENTO, E. F.; SOUZA, G. S.; MELO, M. F. Identificação das causas de perdas pós-colheita de cenoura no varejo, BrasíliaDF. Horticultura Brasileira, Brasília, v. 20, n. 2, p.241-245, junho 2002.

LUENGO, R. F. A.; CALBO, A. G. Pós-colheita de Hortaliças: o produtor pergunta, a Embrapa responde. Brasília: Embrapa Informação Tecnológica, 2011.

MAIA, V. M. et al. Tipos e intensidade de danos mecânicos em bananas 'prata-anã' ao longo da cadeia de comercialização. Revista Brasileira de Fruticultura, Jaboticabal, v. 30, n. 2, p 365-370. 2008.

PARISI, M. C. M.; HENRIQUE, C. M.; PRATI, P. Perdas pós-colheita: um gargalo na produção de alimentos. Pesquisa \& Tecnologia, v.6, n.2, 2012.

RIBEIRO, T. P.; LIMA, M. A. C.; SOUZA, S. O.; ARAÚJO, J. L. P. Perdas pós-colheita em uva de mesa registradas em casas de embalagem e em mercado distribuidor. Revista Caatinga,

Mossoró, v. 27, n. 1, p. 67 - 74, jan. - mar., 2014.

SANTOS, K.; VIEIRA, W. Destino final: o lixo.

Comunicado especial: Abastecer Brasil. Associação

Brasileira das Centrais de

Abastecimento, n.5. p.8-12. 2011.
SILVA, A. R.; NECHET, D. Características Climáticas de Alguns Municípios Produtores de Soja do estado do Pará. In: CONGRESSO BRASILEIRO DE METEOROLOGIA, Edição XIV, 2006. Trabalho completo. Disponível em: http:// www.cbmet.com/edicoes.php?pageNum

Recordset_busca $=4 \&$ totalRows_Recordset_busca $=1006 \&$ cgid=14. Acesso em: 10 de Agosto de 2016 .

SOUZA, V. J. Padronização,

Classificação, Rotulagem,

Embalagem de Hortaliças (Alface,

Banana, Batata, Cebola, Cenoura, Couve-flor, Pepino, Pimentão e

Tomate.). Secretaria de Estado do

Desenvolvimento Rural e da Agricultura.

Companhia Integrada de Desenvolvimento

Agrícola de Santa Catarina. 152p.

TOFANELLI, M. B. D.; FERNANDES, M. S.; CARRIJO, N. S.; MARTINS FILHO, O. B.

Levantamento de perdas em hortaliças frescas na rede varejista de Mineiros. Horticultura

Brasileira, v. 27, p. 116-120, 2009.

TOFANELLI, M. B. D.; FERNANDES, M. S.; MARTINS FILHO, O. B.; CARRIJO, N. S. Perdas de frutas frescas no comércio varejista de Mineiros-GO: um estudo de caso. Revista Brasileira de Fruticultura, v. 29, n. 3, p. 513-517, Dezembro 2007.

VILELA, N. J.; LANA, M. M.; NASCIMENTO, E. F.; MAKISHIMA, N. Perdas na comercialização de hortaliças em uma rede varejista do Distrito Federal. Cadernos de Ciência e Tecnologia, n. 20, p. 521-541, 2003.

Recebido para publicação em 16/2/2018 e aprovado em 25/5/2018.

Revista Brasileira de Agropecuária Sustentável (RBAS), v.8, n.2, p.106-114, Junho, 2018 